This document is the accepted manuscript version of the following article: C. Wäckerlin, C. Iacovita, D. Chylarecka, P. Fesser, T. A. Jung, N. Ballav Assembly of 2D ionic layers by reaction of alkali halides with the organic electrophile 7,7,8,8tetracyano-p-quinodimethane (TCNQ)

Chemical Communications, 2011, 47, 9146, https://dx.doi.org/10.1039/c1cc12519b

\title{
Assembly of 2D Ionic Layers by Reaction of Alkali Halides with the Organic Electrophile 7,7,8,8-Tetracyano-p-quinodimethane (TCNQ) ††
}

\author{
Christian Wäckerlin, ${ }^{\mathrm{a}}$ Cristian Iacovita, ${ }^{\mathrm{b}}$ Dorota Chylarecka, ${ }^{\mathrm{a}}$ Petra Fesser, \\ Thomas A. Jung*,a and Nirmalya Ballav*,a
}

5 Received (in XXX, XXX) Xth XXXXXXXXX 20XX, Accepted Xth XXXXXXXXX 20XX

DOI: $10.1039 / b 000000 x$

Sublimation of alkali halides ( $\mathrm{NaCl}$ and $\mathrm{LiCl}$ ) onto a preassembled hydrogen-bonded layer of TCNQ on Au(111) resulted in the formation of $2 \mathrm{D}$ ionic layers via a direct 10 charge-transfer reaction without involvement of the substrate. The presented approach allows for the fabrication of different ionic layers, decoupled from the substrate and offering new, potentially interesting properties.

Recently, the observation of chemical reactions at surfaces by 15 scanning probe microscopes has gained significant attention, both for individual reagents being moved into sufficient proximity, as well as through the observation of an ensemble of molecules confined to surfaces. ${ }^{1}$ Among the general case of redox reactions performed in surface confinement ${ }^{2}$ we here ${ }_{20}$ put the emphasis on those which can be used to influence the self-assembly.

The remarkable electron-affinity of 7,7,8,8-tetracyano- $p$ quinodimethane (TCNQ) permits not only charge-transfer (CT) with metals and organic electron-donors, but also CT by 25 oxidation of halogens, i.e. in alkali halides. ${ }^{3 \mathrm{a}, 3 \mathrm{~b}}$ The products of the reaction show interesting properties, i.e. high conductivity or magnetism. ${ }^{3}$ In this paper, we study the reaction of $\mathrm{NaCl}$ and $\mathrm{LiCl}$ with TCNQ on surface and discuss the CT processes between the adsorbates as well as with the 30 substrate.

We use a CT reaction between sublimed TCNQ and $\mathrm{NaCl}$, both in a submonolayer regime, on $\mathrm{Au}(111)$ as a design concept to fabricate two-dimensional (2D) ionic layers. ${ }^{4}$ In this 'solvent free' dry ultra-highvacuum environment, we 35 perform spectro-microscopy correlation experiments involving scanning tunneling microscopy (STM) and photoelectron spectroscopy to demonstrate that CT exclusively occurs between the reactants, and not with the $\mathrm{Au}(111)$ substrate.

40 The self-assembly of TCNQ on an Au(111) as probed by STM (Fig. 1a) which in this case has been predominantly attributed to H-bonding of the cyanogroups. ${ }^{5}$ Sublimation of $\mathrm{NaCl}$ onto $\mathrm{TCNQ} / \mathrm{Au}(111)$ drastically changes the molecular arrangement as clearly visible in both large scale (Fig. 1b) and 45 high resolution STM images (Fig. 1c). The latter image contains a vacancy defect ' 1 ' ' in the $2 \mathrm{D}$ molecular layer which allows for the unambiguous identification of the adsorption geometry. The four-round protrusions ' 2 ' appear due to the arrangement of four-cyanogroups from the adjacent four ${ }_{50}$ TCNQ molecules. This assigned structure is supported by the fact that next to the vacancy ' 3 ' only three protrusions are observed.
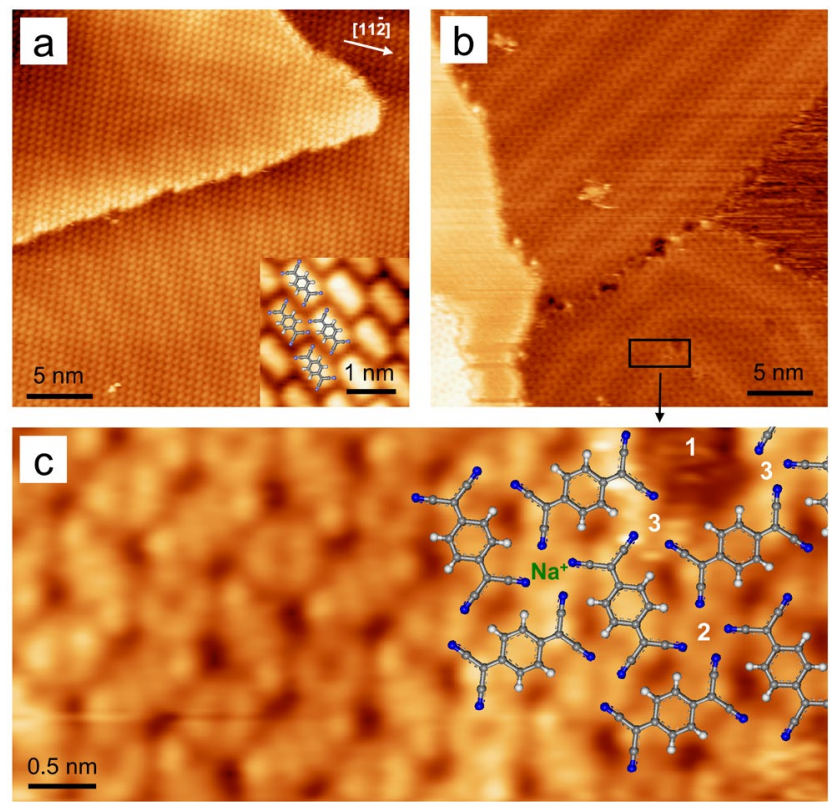

55 Fig. 1 STM image of (a) TCNQ layer on $\mathrm{Au}(111)$ and (b,c) TCNQ layer on $\mathrm{Au}(111)$ after addition of $\mathrm{NaCl}$.

In order to explore the mechanism behind the drastic change in the molecular assembly of TCNQ upon addition of $\mathrm{NaCl}$ we 60 have employed X-ray photoelectron spectroscopy (XPS) (Fig. 2a). TCNQ in a multilayer exhibits a single N1s core-level signal with a binding energy of $\sim 399.1 \mathrm{eV}$ and a C1s signal composed of two components $(\sim 284.95 \mathrm{eV}$ and $\sim 286.3 \mathrm{eV}$; ratio $\sim 8: 4$ ) characteristic for neutral TCNQ as observed in ${ }_{65}$ bulk TCNQ (the shake-up feature is also observed). ${ }^{6 a}$ For a monolayer of TCNQ on Au(111), both the N1s $(\sim 398.7 \mathrm{eV})$ and $\mathrm{C} 1 \mathrm{~s}(\sim 284.65 \mathrm{eV}$ and $\sim 285.9 \mathrm{eV})$ binding energies are slightly reduced presumably due to many-body effects. ${ }^{7 \text { a }}$ The C1s peak shape (i.e. the 8:4 ratio) clearly reveals that TCNQ 70 remains neutral on $\mathrm{Au}(111)$ - a conclusion also supported by STM and scanning tunneling spectroscopy data: the 
herringbone reonstruction persists the deposition of a full monolayer of TCNQ and the highest occupied molecular orbital (HOMO) also survives the adsorption process. ${ }^{5}$
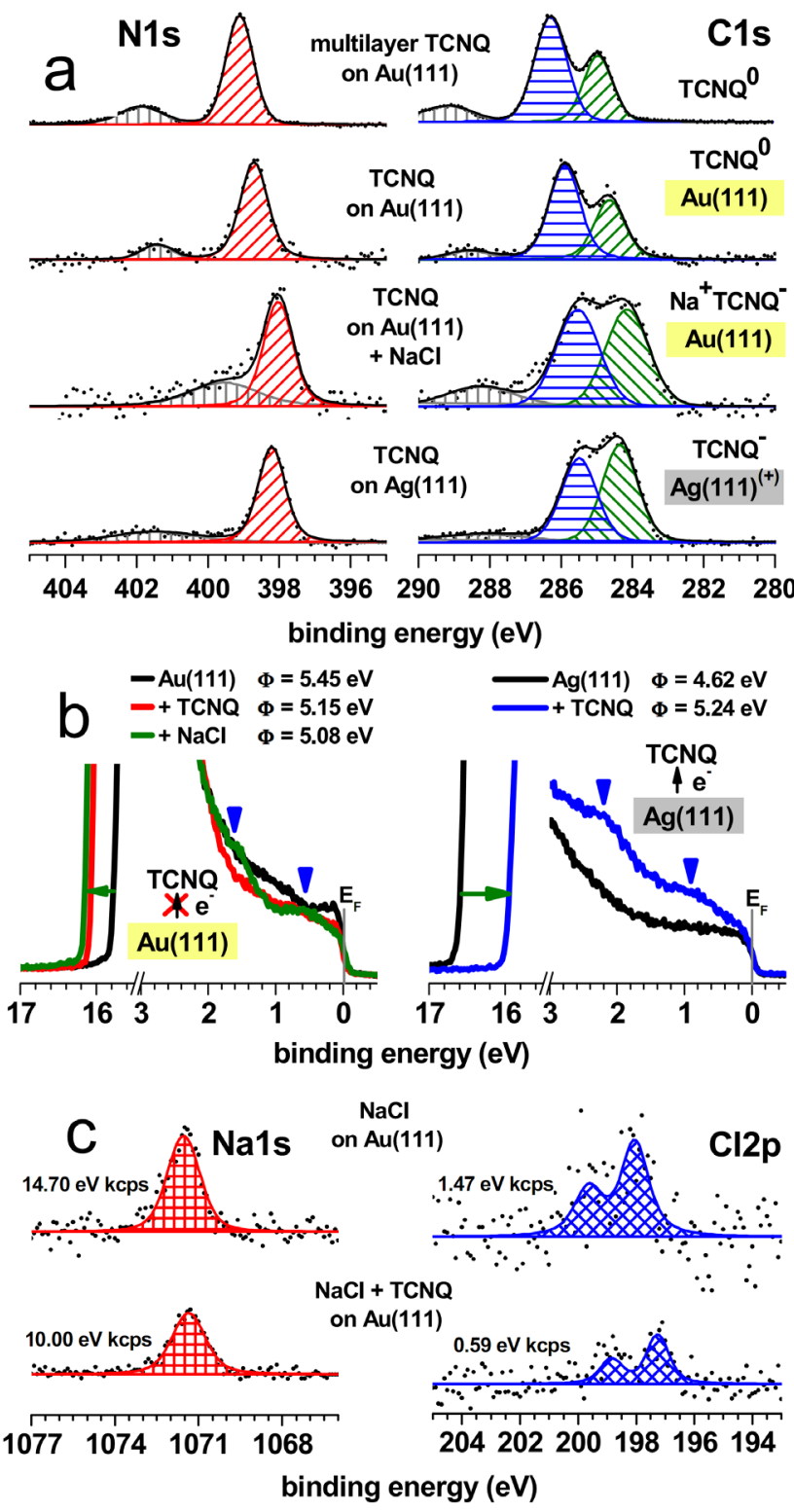

5 Fig. 2 Photoemission spectroscopy data towards the assignment of the species in the reacted and reorganized surface layer: (a) N1s and C1s XP spectra show evidence for neutral (TCNQ/Au(111)) and negatively charged TCNQ, accompanied by aromatization (TCNQ+NaCl/Au(111) and $\mathrm{TCNQ} / \mathrm{Ag}(111))$ derives from the characteristic $\mathrm{C} 1 \mathrm{~s}$ peak shapes. ${ }^{6 \mathrm{a}, 6 \mathrm{~b}}$

10 (b) UP spectra provide evidence for a substrate-to-molecule CT in the case of TCNQ/Ag(111) while no such CT occurs for TCNQ/Au(111) and $\mathrm{TCNQ}+\mathrm{NaCl} / \mathrm{Au}(111)$. The green arrows indicate the shift in the secondary electron cut-off which relates to the sample work function $(\Phi) .{ }^{7 b}$ (c) Na1s and $\mathrm{Cl} 2 \mathrm{p} \mathrm{XP}$ spectra of $\mathrm{NaCl} / \mathrm{Au}(111)$ before and after 15 addition of TCNQ shows a decrease of the $\mathrm{Cl} / \mathrm{Na}$ ratio, indicating the loss of chlorine. The numbers give the integrated peak intensity of the respective signals.

The addition of $\mathrm{NaCl}$ significantly lowers the $\mathrm{N} 1 \mathrm{~s}(\sim 397.95$ $\mathrm{eV})$ and $\mathrm{C} 1 \mathrm{~s}(\sim 284.15 \mathrm{eV}$ and $\sim 285.55 \mathrm{eV})$ binding energies 20 and considerably changes the $\mathrm{C} 1 \mathrm{~s}$ peak shape. Now the two $\mathrm{C} 1 \mathrm{~s}$ peaks are in $\sim 6: 6$ ratio, which is characteristic for
[TCNQ] $]^{-}$, as previously observed for bulk $\mathrm{Li}^{+}[\mathrm{TCNQ}]^{-6 \mathrm{~b}}$ Interestingly, without the addition of $\mathrm{NaCl}$, very similar $\mathrm{N} 1 \mathrm{~s}$ $(\sim 398.2 \mathrm{eV})$ and $\mathrm{C} 1 \mathrm{~s}(\sim 284.35 \mathrm{eV}$ and $\sim 285.5 \mathrm{eV})$ binding 25 energies as well a similar $\mathrm{C} 1 \mathrm{~s}$ peak shape are observed in our data for $\mathrm{TCNQ} / \mathrm{Ag}(111)$. This implies the presence of negatively charged TCNQ through substrate-to-molecule CT, as recently observed for TCNQ on $\mathrm{Cu}(001)^{8 \mathrm{a}}$ and for $\mathrm{Ag}$ nanoparticles. ${ }^{8 \mathrm{~b}}$ The addition of $\mathrm{LiCl}$ instead of $\mathrm{NaCl}$ onto ${ }_{30} \mathrm{TCNQ} / \mathrm{Au}(111)$ leads to very similar changes in self-assemby and XP spectra (Figs. S1 and S2 in ESI $\dagger$ ) and demonstrates that the reaction of TCNQ with salts provides a general toolbox to direct self-assembly in surface supported layers.

The XPS data together with the STM observations clearly 35 demonstrate that upon addition of $\mathrm{NaCl}$ a $\mathrm{CT}$ reaction on $\mathrm{Au}(111)$ surface occurred which resulted in the conversion of TCNQ to [TCNQ] $]^{-}$As a consequence of the CT reaction, the initial H-bonded self-assembly was modified towards a 2D ionic layer. In order to clearly distingush the observed CT 40 reaction between TCNQ and $\mathrm{NaCl}$ on $\mathrm{Au}(111)$ from substrateto-molecule $\mathrm{CT}$ as observed for $\mathrm{TCNQ} / \mathrm{Ag}(111)$, we have employed ultra-violet photoelectron spectroscopy (UPS) (Fig. $2 b)$. Besides the valence electronic structure, UPS also yields information on substrate-to-molecule CT which is strongly 45 influencing the vacuum level at the surface due to formation of an additional electric dipole therby changeing the measured sample workfunction $(\Phi) .^{7 \mathrm{~b}}$

In the case of substrate-to-molecule $\mathrm{CT}$ reaction: as realized on the basis of XPS data for $\mathrm{TCNQ} / \operatorname{Ag}(111)$, an ${ }_{50}$ increase of the sample workfunction is expected due to the formation of a negatively charged TCNQ layer. Indeed, such an increase in the workfunction $(\Delta \approx 0.62 \mathrm{eV})$ is observed for TCNQ/Ag(111) (Fig. 2b, right). On the contrary, for the $\mathrm{TCNQ} / \mathrm{Au}(111)$ and $\mathrm{TCNQ}+\mathrm{NaCl} / \mathrm{Au}(111)$ systems the 55 workfunction compared to the clean substrate is decreased by $\sim 0.30 \mathrm{eV}$ and $\sim 0.37 \mathrm{eV}$, respectively and clearly excludes the possibility of substrate-to-molecule CT reaction (Fig. 2b left, green arrow).

Furthermore, for both systems exhibiting CT, ${ }_{60} \mathrm{TCNQ}+\mathrm{NaCl} / \mathrm{Au}(111)$ and $\mathrm{TCNQ} / \mathrm{Ag}(111)$, the UP spectra display two new features in the valence region (blue and orange triangles) corresponding to the (partial) occupation of the former lowest unoccupied molecular orbital (LUMO), very similar to the UP spectra measured on bulk $\mathrm{K}^{+}[\mathrm{TCNQ}]^{-6 c}$ ${ }_{65}$ The STM images, recorded with a bias voltage close to this resonance at $\sim 1.5 \mathrm{eV}$ yield a high intra-molecular contrast for the $\mathrm{TCNQ}+\mathrm{NaCl} / \mathrm{Au}(111)$ system (Fig. 1c, c.f. Fig. S3 in ESI $\dagger$ for more STM data). Notably, similar STM images of intramolecular resolution have been obtained by tunneling into 70 presumably the same molecular orbital on the TCNQ/Au(111) system. $^{5}$ In addition, when TCNQ is added onto $\mathrm{NaCl} / \mathrm{Au}(111)$ the Na1s and $\mathrm{Cl} 2 \mathrm{p}$ XPS signals (Fig. 1c) show a decrease of the $\mathrm{Cl} / \mathrm{Na}$ ratio by a factor of 1.70 upon sublimation of TCNQ. This decrease indicates a partial loss of 75 chlorine according to the following reaction: $\mathrm{Cl}^{-}+$TCNQ $\rightarrow$ $1 / 2 \mathbf{C l}_{2}+[\mathbf{T C N Q}]^{-3 \mathrm{a}, 9}$ In consequence, the structural rearrangements shown in Fig. 1c can easily be explained on the basis of an ionic assembly of [TCNQ] $]^{-}$with a $\mathrm{Na}^{+}$ion sitting next to four cyano groups ' 2 '. The electron charge is 
fully compensated over the whole layer by the depicted coordination. Notably, adsorbed $\mathrm{Cl}_{2}\left(\mathrm{Cl}_{2} \mathrm{p}_{3 / 2} \text { at } \sim 200.2 \mathrm{eV}\right)^{10}$ was not observed, suggesting a rapid sublimation of molecular chlorine into the vacuum.

5 In view of drawing an analogy for the assembly of TCNQ on noble metals $(\mathrm{Cu}, \mathrm{Ag}, \mathrm{Au})$, charge transfer has been observed in $\mathrm{TCNQ} / \mathrm{Cu}(001)^{8 \mathrm{a}}$ and $\mathrm{TCNQ} / \operatorname{Ag}(111)^{8 \mathrm{~b}}$ cases but not for TCNQ/Au(111).

Figure 3 represents an STM image of TCNQ on $\operatorname{Ag}(111)$. In 10 between the molecules one can identify points of either dark or bright contrast, which were not observed in the case the TCNQ monolayer assembled Au(111) (Fig. 1a). We tentatively assign those features as $\mathrm{Ag}$ vacancies and $\mathrm{Ag}$ atoms, respectively. The lift-up of Ag surface atoms and their 15 inclusion into the layer of TCNQ is in agreement with the observed substrate to molecule CT and is qualitatively similar to $\mathrm{CT}$ induced rearrangement of substrate atoms at the $\mathrm{TCNQ} / \mathrm{Cu}(001)$ interface. $^{8 \mathrm{a}}$ Notably, the $\mathrm{Ag}(111)$ and the $\mathrm{Cu}(001)$ surfaces differ in their symmetry and lattice 20 constants. As a consequence, the epitaxy and interaction of any periodic layer with these substrates is also expected to differ. On $\operatorname{Ag}(111)$ the arrangement of the vacancies/depressions is dynamic at room-temperature in the $\sim 2$ minute interval between the two subsequent STM scans 25 (Fig. 3a\&b, overview STM images Fig. S4 in ESI†). Remarkably, the number of vacancies remains practically constant (Table S1 in ESI $\uparrow$ ), thereby suggesting that the system is geometrically frustrated, i.e. the density of the vacancies is governed by geometric constraints in the $30 \mathrm{TCNQ} / \operatorname{Ag}(111)$ system.
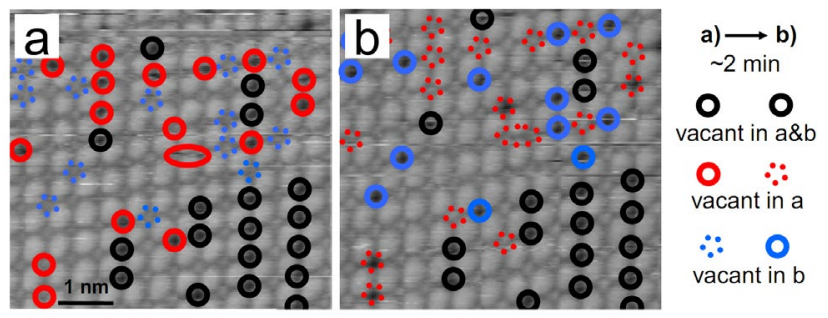

Fig. 3 STM images of TCNQ/Ag(111) in two subsequent scans (a) and (b) with observed dynamic arrangment of vacancies (circles).

35 In summary, we have demonstrated an 'on surface' chemical reaction between TCNQ and $\mathrm{NaCl}$ on $\mathrm{Au}(111)$, which led to the formation of an extended ionic 2D layer. Sublimation of alkali halides is simple and therefore this approach is of a more general use to obtain extended (few hundred nanometer) ${ }_{40} 2 \mathrm{D}$ ionic layers. By choosing various combinations of other salts and TCNQ (or similar electron acceptors), ultra-thin ionic layers with tunable electronic and magnetic properties can be prepared without having to rely on i.e. alkali metals, where excess atoms can easily undergo CT with the ${ }_{45}$ substrate. ${ }^{11}$ In particular, the ionic coordination network on the $\mathrm{Au}(111)$ surface is found to be decoupled from the substrate.

This work was financially supported by the Swiss National Science Foundation (SNSF) and National Center of ${ }_{50}$ Competence in Research (NCCR), Switzerland. NB thanks Holcim Foundation for the Advancement of Scientific
Research, Switzerland for a research scholarship. The authors thank François Diederich for helpful scientific discussions and Rolf Schelldorfer for technical support.

55

${ }^{a}$ Laboratory for Micro- and Nanotechnology, Paul Scherrer Institute, 5232 Villigen, Switzerland.E-mail:nirmalya.ballav@psi.ch; thomas.jung@psi.ch; Fax: +41-56-310-2646; Tel: +41-56-310-4518 ${ }^{b}$ Department of Physics, University of Basel, 4056 Basel, Switzerland

$6{ }^{c}{ }^{c}$ Laboratory for Organic Chemistry, Department of Chemistry and Applied Biosciences, ETH Zürich, 8093 Zürich, Switzerland

$\dagger$ Electronic Supplementary Information (ESI) available: Data on the reaction of $\mathrm{TCNQ} / \mathrm{Au}(111)$ with $\mathrm{LiCl}$, additional STM data and general experimental conditions including STM tunneling parameters, See 65 DOI: $10.1039 / \mathrm{b} 000000 \mathrm{x} /$

\$ This article is a part of a ChemComm web-based themed issue on molecule-based surface chemistry.

\section{Notes and references}

70 1. (a) A. Gourdon, Angew. Chem. Int. Ed., 2008, 47, 6950-6953; (b) D. F. Perepichka and F. Rosei, Science, 2009, 323, 216-217; (c) F. Mohn, J. Repp, L. Gross, G. Meyer, M. S. Dyer, and M. Persson, Phys. Rev. Lett., 2010, 105, 266102; (d) P. Fesser, C. Iacovita, C. Wäckerlin, S. Vijayaraghavan, N. Ballav, K. Howes, J. Gisselbrecht,

75 M. Crobu, C. Boudon, M. Stöhr, T. A. Jung, and F. Diederich, Chem. Eur. J., 2011, 17, 5246-5250.

2. F. Buchner, K. Flechtner, Y. Bai, E. Zillner, I. Kellner, H.-P. Steinrück, H. Marbach, and J. M. Gottfried, J. Phys. Chem. C, 2008, 112, 15458-15465.

80 3. (a) L. R. Melby, R. J. Harder, W. R. Hertler, W. Mahler, R. E. Benson, and W. E. Mochel, J. Am. Chem. Soc., 1962, 84, 3374-3387. (b) J. Ferraris, D. O. Cowan, V. Walatka, and J. H. Perlstein, J. Am. Chem. Soc., 1973, 95, 948-949; (c) R. Jain, K. Kabir, J. B. Gilroy, K. A. R. Mitchell, K.-chung Wong, and R. G. Hicks, Nature, 2007, 445, 291-294.

4. (a) S. L. Tait, Y. Wang, G. Costantini, N. Lin, A. Baraldi, F. Esch, L. Petaccia, S. Lizzit, and K. Kern, J. Am. Chem. Soc., 2008, 130, 21082113; (b) T.-C. Tseng, C. Lin, X. Shi, S. L. Tait, X. Liu, U. Starke, N. Lin, R. Zhang, C. Minot, M. A. Van Hove, J. I. Cerdá, and K. $90 \quad$ Kern, Phys. Rev. B, 2009, 80, 155458; (c) S. Stepanow, R. Ohmann, F. Leroy, N. Lin, T. Strunskus, C. Wöll, and K. Kern, ACS Nano, 2010, 4, 1813-1820; (d) X. Q. Shi, C. Lin, C. Minot, T.-C. Tseng, S. L. Tait, N. Lin, R. Q. Zhang, K. Kern, J. I. Cerdá, and M. A. Van Hove, J. Phys. Chem. C, 2010, 114, 17197-17204.

95 5. I. Torrente, K. Franke, and J. Pascual, Int. J. Mass. Spectrom., 2008, 277, 269-273;

6. (a) J. M. Lindquist and J. C. Hemminger, J. Phys. Chem., 1988, 92, 1394-1396; (b) J. M. Lindquist and J. C. Hemminger, Chem. Matr., 1989, 1, 72-78; (c) W. D. Grobman, R. A. Pollak, D. E. Eastman, E. 100 T. Maas, and B. A. Scott, Phys. Rev. Lett., 1974, 32, 534.

7. (a) S. Hüfner, Photoelectron spectroscopy: principles and applications, Springer, Berlin, 3rd edn., 2003. (b) H. Ishii, K. Sugiyama, E. Ito, and K. Seki, Adv. Mater., 1999, 11, 605-625.

8. (a) T.-C. Tseng, C. Urban, Y. Wang, R. Otero, S. L. Tait, M. Alcamí, 105 D. Écija, M. Trelka, J. M. Gallego, N. Lin, M. Konuma, U. Starke, A. Nefedov, A. Langner, C. Wöll, M. Á. Herranz, F. Martín, N. Martín, K. Kern, and R. Miranda, Nat. Chem., 2010, 2, 374-379; (b) I. S. Chae, S. W. Kang, J. Y. Park, Y.-G. Lee, J. H. Lee, J. Won, and Y. S. Kang, Angew. Chem. Int. Ed., 2011, 50, 2982-2985.

110 9. (a) J. Farges, A. Brau, and P. Dupuis, Solid State Commun., 1985, 54, 531-535; (b) X.-L. Mo, G.-R. Chen, Q.-J. Cai, Z.-Y. Fan, H.-H. Xu, Y. Yao, J. Yang, H.-H. Gu, and Z.-Y. Hua, Thin Solid Films, 2003, 436, 259-263; (c) E. T. Maas Jr., Mat. Res. Bull., 1974, 9, 815-826.

10. H. Piao, K. Adib, and M. A. Barteau, Surf. Sci., 2004, 557, 13-20.

115 11. J. L. LaRue, J. D. White, N. H. Nahler, Z. Liu, Y. Sun, P. A. Pianetta, D. J. Auerbach, and A. M. Wodtke, J. Chem. Phys., 2008, 129, 024709 . 